https://doi.org/10.22364/hssl.27.2.01

\title{
ORGANISATIONAL INNOVATION SITUATION ANALYSIS: IN SEARCH OF A NEW MEASUREMENT MODEL ${ }^{1}$
}

\section{Ilona Baumane-Vitoliṇa}

Dr. oec.

\section{Jeḷena Luca}

Mg. oec.

\begin{abstract}
In a globalised world organisational innovation is one of the key factors for the development of a company and perceiving its competitiveness. Enterprises deal with the difficulty of identifying factors and elements for successful implementation of organisational innovation.

According to a recent scientific debate, it is a challenge to find the perfect metric as organisational innovation measurement is complicated to perform. There are frameworks of measurement of organisational innovations (for example, Dominant Diamond model, Innovation Funnel, Innovation Value Chain and Oslo Manual), but they are proved to have drawbacks that makes it difficult to perform analysis. Recent studies have drawn to the necessity to develop a framework that will avoid the disadvantages of existing models that is the main purpose of this article. Several studies have pointed out a few elements necessary to look at - data usable not only for analysis itself, but for the policy making as well; and a measurement framework to capture the organisational innovations. This article looks at different definitions and metrics of organisational innovations applicable with the system approach, coming to the conclusion that for the development of effective innovation measurement it is needed to develop a conceptual framework with 5 dimensions: 1) Innovation ability and strategy; (2) Innovation Management ability; (3) Linkages and accessing knowledge; (4) Organization and culture; and (5) Innovation Results. To identify the current situation in the Baltic States and to understand where to test the model, the authors have performed a multidimensional analysis of the fields of innovative business by using correlation and regression analysis according to the indicators of Finance, Employment and Investments. These indicators were chosen on the basis of European Union studies and their results that are generally accepted and recognised as qualitative. The data of the Central Statistical Bureau and the Bank of Latvia has been used. The main conclusions of this study are that Latvia falls behind the other Baltic States in EU Innovation rank and the main reason is a low level of innovations;
\end{abstract}

1 The research for this article has been supported by the European Regional Development Fund post-doc research support No. 1.1.1.2/VIAA/1/16/016. 
Analysing the correlation between number of employees, turnover, investment in ICT and venture investments showed only a relationship between number of employees and investment in ICT, regression analysis showed that $80 \%$ of the investment in ICT is explained by an increase in the number of employees that supports the given model, but the field of an enterprise does not have any effect on the success of innovative companies. The purpose of this article is to build a new framework of analysis of organisational innovation to test this model and use it in the further studies. This article assesses developments in currently performed studies looking at measurement of organisational innovation based on the recent issue of the Oslo manual and studies in Europe to create a theoretical framework for further studies. The results can be used for measuring organisational innovation more effectively, as well as the implementation of organisational innovations. The developed model is the next step for the research that is planned to perform, as well further researchers could use the model.

Keywords: Latvia, organisational innovation, measurement of organisational innovation, theoretical framework, organisational innovation definitions

\section{Introduction}

Innovative business has complex characteristics, innovative companies must not only update through the development, but must learn to implement new ideas and think out of the box. Innovativeness shows the potential of the company that could be defined by resources, financial and legal opportunities, techniques, technologies and culture. Innovative potential is the most important priority for the innovative company, intensity of innovation process will show performance results expressed in effectiveness of innovations.

According to Schumpeter (1939) innovation is essential for sustainable growth and economic development. In the modern economic society, innovation processes occur at the different levels from the enterprise to the national. Innovation increases competitiveness of new and of existing enterprises. There exists a thought that big enterprises, as well as developed countries which have resources for innovation processes, develop with a negative effect on innovation (Schumpeter, 1939). Once an enterprise has outreached a size of SME it requires a better control system, they lose ability to innovate as freely as they could (Turner, J. R., Ledwith, A., \& Kelly, J. F., 2010), and thus enterprises are turning to improvement rather to innovations (Gopalakrishnan, S., Bierly P. \& Kessler, E. H., 1999). The vision of innovation becomes more complex and harder to implement (Agle, B. R., Mitchell R. K. \& Sonnenfeld J. A., 1999). This theory has an opposite opinion of higher opportunities for enterprises in wealthy thicker markets comparing with developing countries (Shane, 2003), when larger firms may put increased resources behind the innovation process 
(Iwamura, Jog, 1991) and Silicon Valley could be the best example of implementation and development of innovations in highly developed and wealthy conditions.

Innovation is defined as the implementation of a new or improved product or process and a new marketing or organisational methods in intercompany operations, workplace organisation and business relations (OECD, 2005). Thus we understand that innovation process is divided into two main groups technological and non-technological innovation, each of them has two categories, for technological it is product and process innovation, for non-technological it is marketing and organisational innovation (Damanpour, F., 2017).

To understand situation in the EU, the authors have looked at the statistical data using the EU Innovation Scoreboard. The European Innovation Scoreboard since 2007 works on factors that impact strengths and weaknesses of European countries in the innovation implementation process. Four dimensions have been developed to analyse innovative rank of the countries: human resources (e.g. where and how people are employed, as well as do they have necessity and willingness to participate in innovation process, students, lifelong students); investments (e.g. government investments in the $R \& D$, venture capital expenditures, is government willing to support innovative companies, where innovative companies invest, comparing $R \& D$ and non- $R \& D$ investments, is the country interesting for investors in the field of innovations); innovation activities that include division of innovation implemented and linkages or how enterprises collaborate with other enterprises, public, government institutions, as well as internationally; employment impacts (e.g. knowledge intensive activities, fast growing enterprises in innovative sectors) and sales impacts (e.g. high tech product, knowledge intensive services exports, new product sales).

According to European Innovation Scoreboard (2018), Latvia is ranked as $3^{\text {rd }}$ country from the end, falling behind other Baltic States. Human resources are considered the strength of Baltic States, but it is necessary to mention countries that are counted as innovative leaders, are decreasing workforce numbers in agriculture and other sectors, though this number of employees is high in Baltic States (employing 23\% of people after the age of 41), that shows high percent of adults employed in agriculture.

Latvia and Lithuania have an advantage of an innovation friendly environment that shows a positive trend during last 6 years, this index has been growing steadily. Estonia which has been the most successful innovative country comparing to other Baltic States has a positive investment index, for last ten years Estonia is interesting for venture investors, government and private companies invest in $R \& D$, as well as innovation processes have been made national level priority. 
Speaking about weaknesses - innovation implementation, Latvia has very low index of innovation that could be a problem for long term sustainable development of the country's development and economic growth, but even innovation leader Sweden has a comparably low index of innovation, it is a weakness in almost all European Union countries. Research systems have drawbacks and are counted as a weak point, Latvian enterprises do not invest in knowledge, in employees, as well as Latvia doesn't have proper and tight relationship between universities and enterprises, there are no unifying and deep research systems that could be used and developed in the future. A lot of even large companies do not have educational centres, not speaking about SME's.

Thus one can come to the conclusion that Latvia falls behind other Baltic States and the main reason of it could be an unwillingness to develop and invest in research, unwillingness to cooperate and thus to get new ideas from outside, implement them in such way to develop together with other European countries.

\section{Research and analysis}

The authors have used the second dimension of European Innovation Scoreboard, 2017 and compared this information with Employment in the fields. To compare EU data and research results, the authors have performed research looking at one of the dimensions using the data of the Bank of Latvia and the Central Statistical Bureau, regression analysis was performed, analysing the fields of activity of innovative companies and their performance in 2016. 7 innovative business sectors were selected (Mining and quarrying (B), Manufacturing (C), Electricity, gas, heating and air conditioning (D), Water supply, sewage, waste management and remediation (E), Wholesale trade, except of motor vehicles and motorcycles (46), Transport and storage $(\mathrm{H})$, Financial and insurance activities (K)), data on their investment in ICT, venture investment and turnover were chosen, complementing the data with number of employees.

To analyse data using regression analysis, a data correlation analysis was initially performed. Analysing the correlation coefficients, it was shown the strongest link is between the number of employees in innovative enterprises and their contribution to ICT (information and communication technologies). This raises the question of whether the use of ICT by enterprises forces companies to grow.

Correlation coefficient shows that there is no connection between number of employees and venture investment, as well as turnover. It means that even small companies can have great foreign investment and have impressive turnover, but innovative enterprises as they develop must have investment in ICT. It agrees with theoretical background mentioned 
above when company is big enough it stops to innovate, but begins to develop, it is hard to say about innovation process due to lack of data but, is obviously that numbers of employees are related to development process in the company and necessity to control their activities.

Correlation analysis does not answer the other question how strong this relationship between number of employees in innovative enterprises and their contribution to ICT is. That is why the authors have used a regression analysis. The purpose of this is to determine whether there is a statistically significant connection between the variables, the analysis of regression, both gives the opportunity to observe common regularities and gives explanation to those that do not fit in the common picture.

Regression analysis explains most of the dispersion with the regularity of the existing variables. Typically, the description of the regression model is based on the ratio of the explained dispersion to the unexplained dispersion. This indicator is called the determinant coefficient and is denoted by R-square. In this case, it is 0.583 , which means that $58 \%$ of the variation of the dependent variable is explained by the variation of the independent variable. The fact that $80 \%$ of investment in ICT is explained by an increase in the number of employees supports the given model. Non-standardised ratios show that at $0 \%$ of employees, investment in ICT would be 1776 thousand EUR, but as the number of employees increases by $1 \%$, the investment volume increases by 0.088 thousand EUR. The standard error coefficient shows the variance of the independent variables. Non-standardized ratios show how the dependent variable varies by changing the dependent variable per unit, while standardized coefficients allow getting the total exposure of each predictor to the dependent variable. An indicator can support or reject a hypothesis with a lack of correlation. In this example, a is significant at 0.076, that proves stated the hypothesis. ICT is factor that increases when company grows. Innovative companies choose investment in ICT as one of the most important factors to their development, but it is important to mention that trend in EU is completely different, innovative leaders reduce number of people in innovative sectors, they invest in ICT, linkages, knowledge and employee education, but decrease number of the staff.

The next step is to determine the significance of a determinism indicator, or F statistics. F is 6.976, at the significance level of $0.076>0.05$. This means that with a probability of $69 \%$ we can say that the number of employees affects the number of contributions to ICT.

The R-square shows that the number of jobs is not related to the volume of investments, only $2.8 \%$ of the model is explained, this requires an in-depth analysis to find out in which way and what factors influence the investment attraction among innovative companies in these areas. Increase in the number of enterprise employees by $1 \%$ for 
0.004 million EUR will increase investment and, in addition, both indicators of significance $>0.05$, therefore, are insignificant.

Similar results are also provided by variance analysis, only $14 \%$ of the model can be explained, and the indicator is not significant. Consequently, it can be concluded that the number of employees does not affect the investment flow among innovative enterprises, as influenced by other factors. Similarly, the authors have also performed analysis of turnover and has come to same results. The results prove the previously made hypothesis that the size of enterprise does not affect turnover or amount of investment to the enterprise. The authors assume that this is due to modern technologies that are used by innovative companies. The question for the further studies is what factors affect amount of investment to the company.

The last point in this analysis would be the residual values that prevent the linear function from being obtained. By looking at these indicators and looking at the resulting graph, it can be said that it is similar to the linear function, but with a positive balance in the manufacturing industry. This means that dispersion is not accidental.

It is also necessary to mention that after conducting the multidimensional analysis author has looked into the data and has come to the conclusion that comparing to EU leaders in Latvia the most people are employed in Manufacturing industries, but this sector has the biggest investment in the ICT, second turnover and venture investments, in the authors opinion which is based on theoretical and practical background this industry needs to head to downsizing of employees, or developing new ways of employing them by growing and developing, as well as improve the linkages, invest in the research system that will show the way to the companies in the sector. This could lead to development of the economy and give positive vibe to long term development. In the authors opinion such practices as foreign brain drain (in little amounts), experience exchange possibilities that will improve situation in general. As well it is worth to mention that the wholesale amount of investment is the lowest of the fields, but has the highest turnover and this trend is the same as in EU where wholesale companies do not invest, do not have venture investments, but have high turnover.

\section{A new measurement model for Organisational measurement}

Performing the analysis has proven the importance of innovation implementation in the companies in Latvia; theoretical background has shown an importance of Organisational Innovation to occur for successful implementation of technological innovation. And here the authors come to the aim of the article - to create a new measurement model for 
Organisational measurement as previously made studies show drawbacks in this field.

In the past different measurement frameworks/models were developed, they show the foundation on which measurement instruments are developed that is a topic of further study. As was mentioned above, scholars proved that one element cannot properly evaluate organisational innovations, so frameworks mentioned below consist of several dimensions looking at organisational innovations through different prospective.

1. First frame for measuring organisational innovations looked at this article is the Dominant Diamond Frame that was proposed by Tidd, Bessant, and Pavitt (Tidd, J., Bessant, J., Pavitt, K., 2005) that is based on Porter's model named as Diamond Model (Porter, M., 1990). The measurement system of this model has 5 dimensions (Mehrizi \& Packinat, 2008).

This model is used in many researches and has potential to be developed at least with one more dimension involving quantity and cost factors (inputs) (e.g. human resources, science and technological infrastructure, that will help to see whole picture of organisation innovations.

2. Second frame used in this research is called Innovation funnel, when lots of ideas come in the big end on the left, and a few finished ideas come out the narrow end on the right, ready to go to market, provide exceptional value, and earn substantial revenues and profits. It's a concept that certainly works in principle, but it does require considerable attention to what happens inside the funnel. (Morris, 2008).

Funnel is divided into 3 parts; (1) inputs define scope, context and character of innovation; (2) it is process of innovation that shows the way and answers the question how to innovate; (3) is a place where the whole innovation process gains economic value. An arrow shows the feedback for the organisation, it is all information gained from the innovation process with succeeded and failed activities that the company must learn of.

Scholars propose metrics of two quite different types. The "soft" metrics are qualitative, sometimes in the form of provocative questions that are intended to get people to think more deeply and effectively about the work they're doing. The "hard" metrics are quantitative, and amenable to statistical analysis (Gamal, 2011).

Despite being one of the most common this measurement model has some limitations trying to measure outputs, but it is under the question if input had only the right ideas, metrics etc. What if the aim and scope were not right in the first place? In reality it is very difficult to suspend or terminate answers. Psychological, mental, and motivational factors affect decision-making and challenge objectivity. Sometimes researcher mistakes tunnel for funnel forgetting or ignoring, the fact that after the first gate there are also several other go/kill points. (Hakkarainen, Kari, Talonen, Tapani, 2014). The authors came to conclusion that this model has more drawbacks 
in research performance and it would be a challenge to improve it so far to get rid of these limitations.

3. The innovation value chain comes from idea of generic value chain as proposed by Porter (1985), he defined an organisation's value chain as a system of five linked primary activities and some support activities that lead to the creation of value for customers. Porter's (1985) idea was used as base for more expanded innovation value chain (Van Horne et al., 2006). They suggest six primary activities (need identification, applied research, innovation development, commercialization, diffusion, and adoption) and some support activities (competency management, infrastructure management, and knowledge management).

Models proposed by Roper et al. (2008) and Ganotakis and Love (2012) who research innovation from the knowledge perspective, refer to (1) knowledge sourcing, to be more precise they look at $R \& D$, trying to find the knowledge shows the openness of the company; (2) knowledge transformation (knowledge transformed into outputs- organisational forms) and (3) knowledge exploitation (entering the market, innovations are transformed into productivity).

But first who talk about innovation value chain were Hansen and Birkinshaw (2007). The innovation value chain is derived from the findings of five large research projects on innovation. In the model by Hansen and Birkinshaw (2007) the innovation value chain is viewed as a sequential, three-phase process that involves idea generation, idea development, and the diffusion of developed concepts. Across all the phases, managers must perform six critical tasks - internal sourcing, cross-unit sourcing, external sourcing, selection, development, and companywide spread of the idea. As well there may be one or more activities that a company excels in - the firm's strongest links. Conversely, there may be one or more activities that a company struggles with - the firm's weakest links.

Innovation value chain helps to understand where, which parts of organisation are needed to look at, which of them need to be improved, which are not so important at the moment. The drawback of the model is that sometimes weakest link is neglected and organisation managers do not evaluate them at all, thus minimizing the ability of the organisation to innovate. One or argument against is that being big and having scale is not a key aspect to competitive advantage and profitability. Measuring the innovation value chain is less effective in social era as the measurement framework could miss some element that happen too fast in these conditions as there is lack of systematic information in organisational innovations.

4. Oslo Manual Innovation measurement framework is proposed by Oslo Manual. Oslo Manual proposes guidelines for collecting and interpreting innovation data that is developed by joint guidance of OECD and Eurostat. 
$3^{\text {rd }}$ edition of Oslo Manual that gives insight in Organisational innovation measurement is result of work of OECD Party of National Experts on Science and Technology Indicators (NESTI) and ESTAT STI Working Group. Provided framework gives an insight based on different theories, using various approaches and views innovations as a system.

The main objects on which Oslo Manual is based are innovation in the organisation, in the case of this research organisational innovation. Linkages with other companies and with research institutions are measured in quantitative and qualitative way. Institutional framework in which firms operate that has many possibilities to give freedom of choices and improve the innovativeness of the company, as well as may restrict it and not to give any opportunity to perform organisational innovations. The role of demand must be looked at as there is no necessity to implement innovation policy if does not positively affect productivity of the company.

Oslo Manual is criticised much less, but the question is - does not it happen because of respect to the OECD or because it has less downsides. But still it is important to mention that subject based approach for innovation-based researches have drawbacks. First of all it has very low valid time period as the turnover of staff is fast; it is almost impossible to compare data sets as there are almost no data on the field of innovation; weak significance and representativeness of response rates as well as subjective point of view could be limitation for the using of this model.

\section{Proposed elements for an organisational innovation measurement model}

Using the previous studies, elements have been pointed out to take into account developing metrics for the measuring of organisational innovation. As organisational innovation is increasing in importance of firm strategy development, but existing are not sufficiently adaptable to the changes in the innovative world due to it fast development and apparition of new variables. Everything mentioned above has been leading to development and creation of new metrics to increase accuracy of the findings that must include:

- Measurement of organisational innovation must consist of combination of implementation of innovation and contribution it gives to the company. Certain inputs must be used for organisational innovation to occur and an exact input depends on the wished contribution from implementation of the organisational innovation, in this case inputs must be pointed out and compared with the outputs.

- The outputs in organisational innovation are unpredictable; it must be taken into account during the research and development of metrics. The inputs to innovation are easy to characterise; they will always be 
resources and assets. The outputs, however, are difficult to characterise, especially before the process is complete.

The outputs are unpredictable because innovation is complex, nonlinear, and risky; responds to opportunities; and inherently includes aspects of serendipity (Gamal, D., 2011). Thus it is not worthy to base research on outputs, but consider them only as side effect, especially taking into account idea that in organisational innovation output may be the input of the next stage of innovation.

- Organisational and culture analysis have to be shown as important factor for a company to perform as it is important to be considered innovative nowadays. One of the desired outputs of any innovative project (even if it failed) is that it improves the image or brand reputation of the company (Maniak, 2015). This is point at which research could see a result of organisational innovations, if the image or brand reputation of the company has been improved after the implementation of the organisational innovation.

- Measurable and non-measurable organisational innovation must be included in research. Measurable innovation has a physical embodiment and cost (tools, technologies, materials, markets, and needs in the situation at hand). But non- measurable organisational innovation more often is considered with connection of knowledge. It is even said that knowledge could be a key factor in implementation and adoption of organisational innovation. Numbers of organisational innovation processes are connected with knowledge and money is invested in that.

- The possibility to make mistakes and to fail has made learning experience in high demand and has put high value to new management style, as well is one of the points of knowledge dimension. Scholars show the examples of failures that led to successful projects. Also, larger industrial firms have produced innovative results by reusing technology from previous projects to use it in different sectors (Chapel, 1997). It is called "multi-project lineage management" (Maniak et al., 2014). Researchers as well have managed to map the knowledge used in a project and its trajectory throughout time (the Concept-Knowledge theory, Hatchuel et al., 2002). It means that it is important to show in the study how many mistakes the company has made during its way to organisational innovation.

- Financial analysis must be performed as well. Real option theory, which gives an estimated value of a company, is based on the aggregated potential output value of its innovation projects according to several scenarios. Tools like the balanced scorecard (from portfolio analysis) are designed to help firms' management teams to improve multiproject management methods. This approach places emphasis on portfolio management tools that promotes idea sharing between units 
in the company and between different types of projects (Sidhu, I., et al., 2016). The drive for innovation must include consideration of the demand side which determines the rate of investment and diffusion (take-up) of organisational innovations.

- Outsourcing has become a trend in innovation (Chesbrough, 2003), as it shows the ability of a company to find, see the perspective and to implement innovation that was developed outside its perimeter. More often it is used by SME's as they do not have R \& D facilities, for large companies outsourcing is more difficult as the question rises, why best organisational innovation idea comes not from their own $R$ \& $D$ department, do they even need to have one. So it is necessary to include the possibility and evaluation of the firm to usage the outsourcing if it is possible with the result of this activity even if it is negative.

- The role of creativity in organisation innovation field has begun to develop. More and more companies rely on creativity management to boost their "creativity capital". Methods like TRIZ or Six Thinking Hats help teams and individuals to be more creative and to use their new ideas for the benefit of the business. (Mann, 1998) Other methods can help to measure the creativity of a person, such as the Guilford Method, which is based on a person's divergent thinking ability (Guilford, 1967). These methods aim at triggering new forms of creativity and therefore, lead to a new need for measurement of creative capacities based on various factors, e.g. the number of ideas shared, their eccentricity level, or the social value of the ideas that is seen in Csikszentmihalyi's Systems Model (Csikszentmihalyi, M., 2014). It is necessary to mention that these ideas are not focused on the individuals' entrepreneurship skills and mindsets. But it would be important to look at creativity capital of the company and evaluate it using the developed metrics.

In talking about organisational innovation two main trends in research could be identified, one tries to measure implementation of organisational innovation, such as $R \& D$ intensity, the other is keener on results, such as patents and patent-related index. It is necessary to understand that the real link between these measures and organisational innovation is not proved and still very unclear. In the research the authors came to conclusion that models that are used in case of measuring organisational innovation exist, but have drawbacks, so propose for the next research paper is to develop new model using tools from existing models, but make it more precise in Latvian economic conditions.

Keeping in mind everything mentioned above the authors propose to base the new measurement tool on Oslo Manual developed by OECD. Including five organisational innovation dimensions: (1) Innovation ability and strategy; (2) Innovation Management ability; (3) Linkages and accessing 
knowledge; (4) Organisation and culture; (5) Innovation Outputs. The aim of this model is to develop a framework which can be used to compare levels of innovation capability between different companies in one/ different sectors to identify priorities for policy and strategy development as for companies as for government bodies.

Before the further development of new organisational innovation measurement tool the authors propose to look at different government developed tools around the world, to have seen the difference between research developed models and government used tool, so it would help to introduce better and more precise tool for measurement.

\section{Conclusion}

- Latvia falls behind Baltic States in being innovative, the country is below the EU average level. The main reasons for that is low innovative power, unwillingness to cooperate within the country between government, educational institutions and enterprises, that is completely different from Innovative leaders. Low level of investment in research, education, innovation, unwillingness to develop companies, middle income trap, lack of highly qualified employees and unwillingness to pay higher salaries now are the key factors for not being innovative and developed.

- Statistical analysis of innovative company working fields has shown correlation between number of employees and investment in ICT, the only factors that had any connation and were dependent one from another that has proved importance of Organisational innovation.

- Analysing the situation led to importance of precise measurement system of Organisational Innovation, previously made model have been proved to have numerous disadvantages, including lack of precise information, no enough dimensions used, high possibility of making mistakes etc.

- Using the literature review and basing on previously made studies important factors for the precise measurement of Organisational innovation have been listed that includes: input and output trends, organisational and culture analysis, possibility to make mistakes and to fail, financial analysis, outsourcing and linkages, creativity.

- Basing on OECD Oslo Manual organisational innovation a new measurement model has been proposed, including 5 dimensions: (1) Innovation ability and strategy; (2) Innovation Management ability;

(3) Linkages and accessing knowledge; (4) Organisation and culture;

(5) Innovation Outputs. 


\section{Proposals}

- Before the further development of new organisational innovation measurement tool the authors propose to look at different government developed tools around the world, to have seen the difference between research developed models and government used tool, so it would help to introduce better and more precise tool for measurement.

- To prove the precise measurement of the model, the authors intend to perform a measurement using existing Oslo Manual model and new one to show the difference in metrics and results.

\section{REFERENCES}

Agle, B. R., Mitchell, R. K. \& Sonnenfeld, J. A. (1999), Who Matters to CEOs? An Investigation of Stakeholder Attributes and Salience, Corporate Performance, and CEO Values. The Academy of Management Journal, 42(5), 507-525.

Chapel, V. (1997), La croissance par l'innovation intensive: de la dynamique d'apprentissage à la revelation d'un modèle industriel - le cas Téfal. Unpublished doctoral dissertation, Ecole des Mines de Paris.

Chesbrough, H. W. (2003), Open Innovation: The New Imperative For Creating And Profiting From Technology. Boston: Harvard Business School Press.

Csikszentmihalyi, M. (2014), The Systems Model of Creativity. Springer Netherlands.

Damanpour, F., Evan, W. M. (1984), Organizational Innovation And Performance: The Problem Of Organizational Lag. Administrative Science Quarterly, 29, 392-409.

Damanpour, F. (2017), Organizational Innovation. Oxford Research Encyclopedia of Business and Management.

European Innovation Scoreboard, 2018 [Online] Available at: https://www.interregeurope. eu/policylearning/news/3806/european-innovation-scoreboard-2018/ (Accessed 21 May 2019)

Gamal, D., Salah, E. T., \& Elrayyes, E. N. (2011), How to measure organization Innovativeness. Technology Innovation and Entrepreneurship Center.

Ganotakis, P., Love, J. H. (2012), The Innovation Value Chain In New Technology-Based Firms : Evidence From The U.K. Journal of Product Innovation management, 29(5), 839-860.

Gopalakrishnan, S., Bierly P. \& Kessler, E. H. (1999), A Reexamination of Product and Process Innovations Using a Knowledge-Based View. The Journal of High Technology Management Research, 10(1), 147-166.

Guilford, J. P. (1967), The Guilford Measures: Measuring A Person's Creativity. [Online] Available at: http://www.senseandsensation.com/2012/03/assessing-creativity.html (Accessed 30 January 2019)

Hakkarainen, K. \& Talonen, T. (2014), The Innovation Funnel Fallacy. International Journal of Innovation Science, 6. 63-72.

Hansen, M. T., \& Birkinshaw, J. (2007), The innovation value chain. Harvard business review, 85(6), 121. 
Hatchuel, A., Weil, B. (2002), C-K Theory: Notions and Applications of a Unified Design Theory. Proceedings of the Herbert Simon International Conference on "Design Sciences".

Iwamura, A., \& Jog, V. M. (1991), Innovators, organization structure and management of the innovation process in the securities industry. Journal of Product Innovation Management, 8(2), 104-116.

von Pechmann, F., Midler, C., Maniak, R., \& Charue-Duboc, F. (2015), Managing systemic and disruptive innovation: lessons from the Renault Zero Emission Initiative. Industrial and corporate change, 24(3), 677-695.

Mann, D.L. (1998), Case Studies in TRIZ: A Comfortable Bicycle Seat. The TRIZ Journal, 12.

Mann, D.L. (2001), The Space Between Many Generic Solutions and My Specific Solution. The TRIZ Journal, 6.

Mehrizi, M., H., R., Pakneiat, M. (2008), Comparative Analysis Of Sectoral Innovation System And Diamond Model (The Case Of Telecom Sector Of Iran), Journal of Technology Management \& Innovation, 3(3), 78-90.

Morris, L. (2008), Innovation Metrics, The Innovation Process and How to Measure It, An InnovationLabs White Paper, InnovationLabs LLC.

OECD, OSLO Manual, The Measurement Of Scientific And Technological Activities, Proposed Guidelines For Collecting And Interpreting Technological Innovation Data, 2005. [Online] Available at: http://www.oecd.org/science/inno/2367614.pdf (Accessed 29 January 2019)

Porter, M. E. (1985), The Competitive Advantage: Creating and Sustaining Superior Performance. NY: Free Press (Republished 1998).

Porter, M. (1990), The Competitive Advantage of Nations. Harward Business Review, March/ April.

Roper, S., Du, J., \& Love, J. H. (2008). Modelling the innovation value chain. Research policy, 37(6-7), 961-977.

Schumpeter, J. A. (1939), Business Cycles: A Theoretical, Historical, and Statistical Analysis of the Capitalist Process. Philadelphia: Porcupine Press.

Shane, S. A. (2003), A General Theory of Entrepreneurship: The Individual-opportunity Nexus. Edward Elgar Publishing.

Sidhu, I., Goubet, J. E., Webber, H., Fredh-Ojala, A., Johnsson, C., \& Pries, J. C. (2016). Berkeley innovation index: an approach for measuring and diagnosing individuals' and organizations' innovation capabilities. Concept paper, February.

Tidd, J., Bessant, J., Pavitt, K. (2005). Managing Innovation Integrating Technological, Market and Organizational Change. John Wiley \& Sons, LTD, Third edition.

Turner, J. R., Ledwith, A., \& Kelly, J. F. (2010), Project management in small to medium-sized enterprises: tailoring the practices to the size of the company. Washington, DC, Project Management Institute.

Van Horne, C. et al., (2006). A Value Based Innovation Model. [Online] Available at: https:// www.researchgate.net/publication/267717765_A_value_based_innovation_model (Accessed 25 January 2019) 